(Pre-print final draft. The paper was published in: Singapore Economic

Review, Vol. 47, No. 1, 2002, pp. 89-100)

\title{
Testing Different Classes of Endogenous Growth Models: Industry Evidence for the New Zealand Economy
}

\author{
Hans-Jürgen Engelbrecht, \\ Department of Applied and International Economics, \\ College of Business, Massey University, \\ Palmerston North, New Zealand. \\ Nathan McLellan, \\ New Zealand Treasury, \\ Wellington, New Zealand.
}

\begin{abstract}
$\operatorname{ABSTRACT}^{\S}$
The endogenous growth literature can be broadly separated into two classes of growth models: Rival human capital models and non-rival 'idea' models. Both classes differ in their positive and normative implications for growth. Following Klenow's (1998) approach, this paper uses industry panel data to investigate which class of growth models might be the most appropriate for the New Zealand economy: Exogenous growth, or one of the two classes of endogenous growth models. In contrast to Klenow's findings for the United States, in the New Zealand case rival human capital models seem more applicable, though none of the models correctly predicts all of the empirical relationships.
\end{abstract}

Keywords: Growth, human capital, ideas, industry data, New Zealand

JEL classification: O3; O41, O5

\footnotetext{
Corresponding author. Tel.: $06 \quad 350 \quad 5799$ 5968; Facsimile: $06 \quad 350$ 5660; E-mail: H.Engelbrecht@massey.ac.nz

$\S$ The views expressed in this paper are those of the authors and do not necessarily reflect those held by the New Zealand Treasury. The second-named author presented an earlier version of this paper at the Econometric Society's Australasian Inaugural Intensive Workshop for Young Scholars, Waikato Management School, Hamilton, New Zealand, 9-10 July 2001. Comments from an anonymous referee are gratefully acknowledged.
} 


\section{INTRODUCTION}

Since the resurgence of research on economic growth in the mid 1980s, attention has turned to the issue of determining which type of growth model best fits the data. In general, the empirical literature in recent years has focussed on whether a generic exogenous or endogenous growth model is most congruent with the empirical evidence. ${ }^{1}$ Klenow and Rodriguez-Clare (1997) noted, however, that there has been disappointingly little empirical work trying to discriminate between the applicability of different endogenous growth models and expressed the hope for more work in this area. ${ }^{2}$ This is an important endeavour, as these models have different positive and normative characteristics and hence support different policy prescriptions.

Klenow (1998) indirectly tested a series of growth models using data for 449 United States (US) manufacturing industries. He ran a series of ordinary least squares (OLS) regressions using time-averaged cross-section data, in order to investigate total factor productivity (TFP) growth relationships, and then used these regression results to evaluate the predictions derived from five growth models. Each of the models can be assigned to one of three different classes: Exogenous growth models, rival human capital accumulation models, and non-rival idea accumulation ('idea') models. The latter two belong to the broader class of endogenous growth models.

\footnotetext{
${ }^{1}$ For surveys of the empirical growth literature see, e.g., Durlauf and Quah (1999), and Temple (1999).

${ }^{2}$ But see, e.g., Jones (1995a,b), Kocherlakota and Yi (1996, 1997), Aghion and Howitt (1998, chapter 12), Funke and Strulik (2000) and Bernanke and Gürkaynak (2001).
} 
For rival human capital models, long-run growth is determined by the accumulation of human capital. In contrast, non-rival 'idea' models point to ideas, embodied in capital and intermediate goods - usually through the R\&D process - as the long-run driver of growth. The policy implications of the rival human capital class of endogenous growth models tend to focus on upgrading human capital, i.e. on schooling and training, and the effect that subsidies and taxes have upon them. The idea accumulation models also emphasize schooling, but, in addition, focus on $R \& D$ and other knowledge spillovers, intellectual property rights, and R\&D tax policy (ibid., p. 4).

While empirical growth research has often been pursued in a cross-country setting, this paper employs the country-specific methodology proposed by Klenow (1998) using available data for New Zealand (NZ). The primary aims of this paper are twofold: 1 . To determine which of the major classes of growth models might best fit the NZ data; 2 . to add to the internationally comparable evidence regarding the applicability of the different types of growth models. We find that, in contrast to Klenow, in the NZ case the rival human capital accumulation models seem more applicable, though none of the models correctly predicts all of the empirical relationships.

Section 2 discusses the estimation technique used to investigate the empirical relationships between TFP growth, output and input price growth, and factor intensities, as well as data issues. Section 3 briefly outlines five specific growth models and their theoretical predictions. Section 4 presents the main NZ estimates of the TFP growth relationships. In addition, we also report sensitivity analyses undertaken in order to test 
the robustness of the main results. Section 5 compares our estimates from section 4 with the theoretical predictions derived from the five growth models outlined in section 3 . Section 6 contains concluding remarks. This is followed by two appendices.

\section{METHODOLOGY AND DATA ISSUES}

Klenow (1998) emphasised results obtained with gross output data, as opposed to results obtained using a value added approach (i.e. net output). His justification for doing so was that the international literature supports a degree of substitutability between value added and materials, which implies that the former approach should be used. ${ }^{3}$ Campbell (1984), in his study of the efficiency of NZ manufacturing industries, also argued that gross output data were the more appropriate measure of output at the sectoral level. Accordingly, this paper focuses on the results obtained with gross output data. ${ }^{4}$ The following are the TFP growth relationships which have been estimated in this paper: ${ }^{5}$

$$
\begin{aligned}
& D E F_{i t}=\beta_{1}+\beta_{2} \operatorname{TFP}_{i t}+\varepsilon_{i t} \\
& \operatorname{TFP}_{i t}=\beta_{1}+\beta_{2} L S_{i t}+\varepsilon_{i t} \\
& \operatorname{TFP}_{i t}=\beta_{1}+\beta_{2} N P L S_{i t}+\varepsilon_{i t} \\
& \operatorname{TFP}_{i t}=\beta_{1}+\beta_{2} C S_{i t}+\beta_{3} M S_{i t}+\varepsilon_{i t} \\
& \operatorname{TFP}_{i t}=\beta_{1}+\beta_{2} C S_{i t}+\beta_{3} M S_{i t}+\beta_{4} C S B C_{i t}+\beta_{5} \text { CSMTE }_{i t}+\beta_{6} M_{S M D E F_{i t}}+\varepsilon_{i t}
\end{aligned}
$$

\footnotetext{
${ }^{3}$ See the review of empirical studies by Bruno (1984).

${ }^{4}$ In Klenow's (1998) study, use of gross and net output led to qualitatively very similar results. This, however, is not the case for NZ. There is a need to further analyse this divergence. In general, it is recognized that use of net instead of gross output industry level data can lead to greatly misleading results (Basu and Fernald, 1995, 1997).

${ }^{5}$ TFP growth relationship (5) differs from Klenow (1998) because the NZ data contain separate capital deflators for the building and construction capital stock as well as the plant, machinery, and equipment capital stock.
} 
where $\mathrm{i}=1, \ldots, 20$ indexes the twenty industries comprising the market sector of the NZ economy (see Appendix A), $t=1, \ldots, 3$ (each time-series observation is a six-year average) and:

DEF Trend annual growth of the output deflator

TFP Trend annual growth of TFP

LS Average labour share

NPLS Average non-production labour share (a proxy for human capital intensity)

CS Average capital share

MS Average materials share

CSBC Product of the average capital share and trend annual growth of the building and construction capital deflator

CSPMTE Product of the average capital share and the trend annual growth of the plant, machinery, and equipment capital deflator

MSMDEF Product of the average materials share and the trend annual growth of the input deflator

$\varepsilon \quad$ Random error term

TFP growth rates have been calculated by subtracting the weighted average of factor input growth (growth of labour, L, capital, K, and intermediate inputs, i.e. materials, M) from output growth, where production elasticities act as weights: 


$$
\dot{A} / A=\dot{Y} / Y-w_{L}(\dot{L} / L)-w_{K}(\dot{K} / K)-w_{M}(\dot{M} / M)
$$

In (6), $w_{L}=(\partial Y / \partial L)(L / Y), w_{K}=(\partial Y / \partial K)(K / Y)$, and $w_{L}=(\partial Y / \partial M)(M / Y)$ are the production elasticities with respect to each input. Instead of following the still common practice of calculating a point-to-point growth rate for each variable, this study estimates trend annual growth rates using OLS, which should be more robust to short-run fluctuations, such as business cycle effects (see, e.g., Temple, 1999, p. 119).

Data are for the period 1978-1995. Most of them are from the Official New Zealand Productivity Research Database (ONZPRDB) supplied by the New Zealand Treasury, the Reserve Bank and the Department of Labour (see Diewert and Lawrence, 1999). For more information about data sources, see Appendix B.

This study uses data for a considerably smaller number of industries than does Klenow (1998). When the regression analysis was performed using a single cross-section of timeaveraged data, the precision of the estimates was poor. In order to overcome this problem we pooled the data. This raised the question of how to divide the total 18-year period into separate time-intervals over which to estimate growth rates. Temple (1999) noted that the choice of time intervals in growth studies to avoid distortions due to business cycle effects remains largely unsettled.

Casual inference of our data seemed to allow identification of three 6-year phases in the growth of GDP: 1978-1983, 1984-1989, and 1990-1995. The phase 1978-1983 was 
characterised by high unemployment and inflation, and "a pattern of cycles of economic 'boom and bust'” (Dalziel and Lattimore, 1999, p. 19). The second phase, 1984-1989, was the reform period of the fourth Labour Government. During this period output stagnated, as the government initiated a comprehensive programme of economic reforms, resulting in a recession. The final period, 1990-1995, was characterised by periods of strong economic growth, as the economy entered the expansionary phase of the business cycle. ${ }^{6}$ While recognising that output trends for some industries may differ from the trend in aggregate output, these periods provide a convenient six-year split for estimation purposes. A formal technique - the linear spline test - was also employed to test for structural breaks in 1984 and 1990. The test provided sample evidence of a structural break in 1984 but not $1990 .^{7}$ Looking at the data, one could also argue that the second phase did not end until 1992. However, a linear spline test provided no sample evidence of a structural break in 1992. It was decided to estimate growth rates over six-year periods. However, as part of the sensitivity analysis different time horizons were utilized to verify the robustness of the regression results (see section 4.2 below).

The trend annual industry TFP growth rates calculated for our three 6-year periods are reported in Engelbrecht and McLellan (2001, Appendix C). They have remained relatively constant over time for manufacturing and service sector industries, with TFP growth fluctuating within a narrow band. There are, however, two industries that are

\footnotetext{
${ }^{6}$ See Dalziel and Lattimore (1999) for a brief introduction to NZ economic developments from 1960 onwards. For more detailed analyses of the dramatic reforms introduced in NZ in the decade following 1984 see, e.g., Silverstone et al. (1996) and Evans et al. (1996). Galt (2000) has synthesized recent thinking about NZ's growth performance.

${ }^{7}$ See an earlier version of this paper for details (Engelbrecht and McLellan, 2001).
} 
notable exceptions: Basic Metal Products and Petroleum, Chemical, Plastics, and Rubber Products. In these industries the range of TFP growth is quite high. Also, primary sector industries experienced a dramatic fall-off in TFP growth over the entire period. In only three industries - Communications, Non Metallic Mineral Products, and Wood and Wood Products - was TFP growth higher over the period 1990-1995 than 1978-1983, with the increases being of small magnitude.

Finally, a word of warning. Diewert and Lawrence (1999, p. 69), commenting on the shortcomings of the NZ data, note: "[i]t is important to express the need for caution in interpreting sectoral and industry productivity results. Sectoral information is likely to be less reliable than aggregate economy wide information.” This has to be borne in mind when interpreting the results of our TFP growth relationship estimation. In fact, data problems cast a large question mark over any analysis of NZ economic growth. ${ }^{8}$ This can only be remedied by improved data becoming available.

\section{GROWTH MODELS AND THEIR THEORETICAL PREDICTIONS}

We now briefly introduce the different growth models and their theoretical predictions about TFP growth relationships (1) to (5). The discussion is based on Klenow (1998). All the models considered have the following common features. There are two industries whose TFP growth rates are compared. There is no uncertainty. Production of the final

${ }^{8}$ See the discussion of the NZ productivity literature in Diewert and Lawrence (1999). Also see Oxley et al. (1999) who, using a time-series based approach, found weak support for an exogenous explanation of NZ growth. Their rejection of an endogenous explanation, however, may have arisen due to measurement problems (ibid., p. 53). 
good $Y$ is achieved by a continuum of profit-maximizing firms combining two intermediate goods $Y_{1}$ and $Y_{2}$ using a Cobb-Douglas (CD) technology. $Y_{1}$ and $Y_{2}$, in turn, are produced by a continuum of firms using human and physical capital. Let $p_{1}\left(p_{2}\right)$ be the price of intermediate good 1 (2). The price of the final good is normalised to equal one. The model implies constant nominal output shares, which in terms of growth rates can be written as:

$$
g_{Y 1}-g_{Y 2}=g_{p 2}-g_{p 1}
$$

where $g_{x}$ denotes the growth rate of $x$. Given this basic framework, the alternative growth models differ in terms of their production technologies for the two intermediate goods and the accumulation technologies for human capital and ideas.

\subsection{Exogenous growth}

It is assumed that the two intermediate goods $Y_{i}$ are produced by firms with the following technologies:

$$
Y_{i t}=Z_{i t}\left(L_{i t} H\right)^{\alpha_{i}} K_{i t}^{\beta_{1}} M_{i t}^{1-\alpha_{i}-\beta_{i}}, \mathrm{i}=1,2 .
$$

where $Z$ is an index of technology, equal to TFP, $L$ is the number of labour hours per worker, $H$ is the level of human capital stock per worker, $K$ is the level of physical capital stock per worker, and $M$ is the level of materials input. $Z$ is determined exogenously and 
grows continuously at the rate of $\mu_{i}$. This implies that growth in the final good $Y$ is also exogenously determined. $L$ and $H$ do not grow over time (in contrast to $K$ and $M$ ). Input markets are competitive and clearing. Given these assumptions, it can be shown that the steady-state growth rate implies the following growth versions of (8):

$$
g_{Y 1}=\mu_{1}+\left(1-\alpha_{1}\right) g_{Y} \quad \text { and } \quad g_{Y 2}=\mu_{2}+\left(1-\alpha_{2}\right) g_{Y} \text {. }
$$

Substituting these into equation (7) yields:

$$
g_{Y 1}-g_{Y 2}=\mu_{1}-\mu_{2}+\left(\alpha_{2}-\alpha_{1}\right) g_{Y}=g_{p 2}-g_{p 1}
$$

Assuming that labour intensity varies exogenously over the two intermediate good industries and is uncorrelated with TFP growth, ${ }^{9}$ and generalizing to $\mathrm{N}$ intermediate goods, this model predicts that industry i should experience a relative price decline of $1 \%$ for every percentage point of above average TFP growth. If the elasticity of substitution between the two intermediate goods in producing the final good is greater than (less than) one, then this model points to a parameter estimate for TFP growth relationship (1) that is less than (greater than) one. How does the model measure up with the other TFP growth relationships? By assumption, it gives no explanation as to why TFP growth is related to labour (including non-production labour), capital, and materials intensity, given that TFP growth is exogenously determined.

\footnotetext{
${ }^{9}$ The latter assumption is reasonably true for our data, i.e. there is only a very weak correlation between TFP growth and labour's share.
} 


\subsection{General human capital accumulation}

This model is an extension of Rebelo (1991). Human capital is general in the sense that it increases the level of production for both intermediate goods by raising the efficiency of labour by the same proportion in each industry:

$$
Y_{i t}=\left(L_{i t} H_{t}\right)^{\alpha_{i}} K_{i t}^{\beta_{i}} M_{i t}^{1-\alpha_{i}-\beta_{i}} \quad, \mathrm{i}=1,2 .
$$

Input markets are assumed to be competitive and clearing. The labour endowment can be allocated between work and human capital accumulation, and human capital grows at a constant rate with a fixed amount of time devoted to its accumulation. Because human capital is not netted out from our (conventionally measured) TFP, faster TFP growth is predicted in more labour-intensive industries:

$$
g_{T F P_{i}}=\alpha_{i} g_{H} \quad, \mathrm{i}=1,2 .
$$

Therefore, the coefficient estimate for TFP growth relationship (2) is predicted to be positive. It can be shown that the steady state growth rate implies the following growth versions of (11): $g_{Y 1}=g_{Y}$ and $g_{Y 2}=g_{Y}$, or:

$$
g_{Y 1}=g_{Y 2}
$$


Therefore, industry output growth is balanced and, given constant nominal output shares, the relative prices of $Y_{1}$ and $Y_{2}$ are constant over time. Thus this model does not predict TFP growth relationship (1). This is because higher TFP growth - driven by human capital accumulation - is paid for in higher wages, thus there is no reduction in industries' marginal cost (and hence price). Prediction of the sign for the other growth relationships depends on their correlation with labour's share. For example, in our data LS is positively correlated with NPLS, indicating that the coefficient sign for the latter should also be positive and statistically significant (TFP growth relationship (3)).

\subsection{Industry-specific human capital accumulation}

In this model the first intermediate good, $Y_{l}$, is produced by workers who possess a higher level of human capital ('skilled workers') relative to the workers who produce the second intermediate good, $Y_{2}$ ('unskilled workers'). The production technologies are:

$$
\begin{aligned}
& Y_{1 t}=\left(L_{1 S t} H_{t}\right)^{\alpha_{1}} K_{1 t}^{\beta_{1}} M_{1 t}^{1-\alpha_{1}-\beta_{1}} \\
& Y_{2 t}=L_{2 U t}{ }_{2} K_{2 t}^{\beta_{2}} M_{2 t}^{1-\alpha_{2}-\beta_{2}}
\end{aligned}
$$

where $L_{S}$ and $L_{U}$ are the number of hours worked by skilled and unskilled workers, respectively. Skilled workers can allocate their time between working and accumulating human capital. The human capital of unskilled workers is assumed constant and normalised to equal one. It is again assumed that input markets are competitive and clearing. In this model skilled workers drive growth, where TFP growth is now determined as follows: 


$$
g_{T F P_{i}}=\alpha_{i} g_{H_{i}} \quad, \mathrm{i}=1,2 .
$$

Therefore, the coefficient estimate for TFP growth relationship (3) is predicted to be positive. Klenow notes that this model does not converge to a balanced growth path because the growth rate of human capital is greater than the growth rate of the final good. This is because the accumulation of human capital is specific to the industry that produces the first intermediate good. Finding the growth versions of (14) and substituting into (7) yields the following:

$$
g_{Y 1}-g_{Y 2}=\alpha_{1} g_{H}+\left(\alpha_{2}-\alpha_{1}\right) g_{Y}=g_{p_{2}}-g_{p_{1}}
$$

$g_{Y}$ is fixed when looking across industries. If it is assumed that LS varies exogenously across industries and that it does not co-vary with NPLS (and therefore TFP, see (15)), equation (16) shows that industries with faster than average TFP growth should exhibit relative price declines (TFP growth relationship (1)). This is because human capital accumulation leads to a relative price decline for the first intermediate good. Prediction of the sign for the other growth relationships depends on their correlation with NPLS.

\subsection{General idea accumulation}

This model is a variation of Romer's (1990) well-known model of imperfect competition with knowledge as a partially excludable, nonrival input. It is 'general' in the sense that 
new ideas are general to both industries that produce the two intermediate goods - where new ideas are embodied in new types of equipment. Each intermediate good is produced by a continuum of firms using the following production technologies, which combine all varieties of physical capital with human capital:

$$
Y_{1}=H_{Y_{1}}^{\alpha_{1}}\left(\int_{0}^{A} x_{1}(i)^{\frac{\sigma-1}{\sigma}} d i\right)^{\frac{\sigma\left(1-\alpha_{1}\right)}{\sigma-1}} ; \quad Y_{2}=H_{Y_{2}}^{\alpha_{2}}\left(\int_{0}^{A} x_{2}(i)^{\frac{\sigma-1}{\sigma}} d i\right)^{\frac{\sigma\left(1-\alpha_{2}\right)}{\sigma-1}}
$$

where $A$ is the number of capital good varieties, $x$ is the quantity of each capital good used in production, and $\sigma$ is the elasticity of substitution. It is assumed that $\sigma$ is less than infinity, i.e. capital varieties are imperfect substitutes. Human capital is held constant. Materials inputs are neglected in the exposition to simplify the analysis. Implicitly, materials input varieties are assumed to grow along with those of capital.

Each capital good variety is produced by a single firm, which obtained its monopoly position by purchasing a production license from the research firm that designed the capital good variety. The stock of capital varieties follows: $A_{t+1}=\delta H_{A} A_{t}$, where $\delta$ is the research productivity parameter and $H_{A}$ the level of human capital devoted to research. This implies knowledge spillovers because the amount of new ideas generated by researchers depends on the stock of ideas from which to learn. Klenow notes that when capital good varieties are assumed to be symmetric, we can write equations (17) as:

$$
Y_{i}=A^{\frac{1-\alpha_{i}}{\sigma-1}} H_{Y_{i}}^{\alpha_{i}} K_{i}^{1-\alpha_{i}} ; \mathrm{i}=1,2
$$


Given (18), it can be established that TFP growth in industry i can be measured as follows:

$$
g_{T F P_{i}}=\left(1-\alpha_{i}\right)\left[g_{A} /(\sigma-1)\right]
$$

That is, TFP growth is a function of the growth of capital good varieties, scaled by a 'substitutability adjusted' capital share. Equation (19) also shows that regressing industry TFP growth on industry capital shares provides an estimate of $g_{A} /(\sigma-1)$. Capital (and materials) shares should thus be positively related to TFP growth (TFP growth relationship (4)), and industry human capital (and implicitly labour) intensity should be negatively correlated with TFP growth (TFP growth relationships (2), (3)).

In this model, $Y, C, K, K_{1}$, and $K_{2}$ all grow at the same rate, and $H_{Y 1}, H_{Y 2}, H_{A}$ are assumed fixed. This, together with the growth versions of (18), and equation (7), yields the following:

$$
g_{Y 1}-g_{Y 2}=\left(\alpha_{2}-\alpha_{1}\right) g_{Y}+g_{T F P_{1}}-g_{T F P_{2}}=g_{P 2}-g_{P 1}
$$

When this is generalised to $\mathrm{N}$ industries, those that exhibit faster than average TFP growth should experience more than proportional relative price declines (TFP growth relationship (1)). Industries use the same capital and materials inputs, however. Therefore 
the model cannot account for why differences in input deflator growth help to explain inter-industry TFP growth differences (TFP growth relationship (5)).

\subsection{Industry-specific idea accumulation}

In this model industry-specific capital goods are assumed in equations (17), i.e. capital goods are exclusive to either one of the two industries, and cannot be used by the other. In this case, research firm $\mathrm{j}$ chooses to specialise in the production of designs for exclusive use by one of the two intermediate goods industries, with one of the following research technologies:

$$
A_{i t+1}=\left[\delta_{i} H_{A i}(j) / H_{A i}^{1-\gamma}\right] A_{i t} \quad ; \mathrm{i}=1,2 .
$$

where $\gamma<1$, implying diminishing returns to scale for the research industry. Klenow notes that, if the variety of inputs for a particular industry is not at all reflected in the effective factor prices, TFP growth for industry $\mathrm{i}$ is determined as follows:

$$
g_{\text {TFP }}=\left(1-\alpha_{i}\right)\left[g_{A_{i}} /(\alpha-1)\right]
$$

If, as is more likely, industry i's price deflator captures some fraction $\omega_{\mathrm{i}}$ of the improvements in variety, equation (22) needs to be replaced by:

$$
g_{\text {TFP }}=\left(1-\omega_{i}\right)\left(1-\alpha_{i}\right)\left[g_{A_{i}} /(\alpha-1)\right]
$$


If $\omega_{\mathrm{I}}>0$, an industry with a high $g_{A}$ (i.e. with many new capital and materials varieties) will be associated with more rapidly declining capital and materials deflators, and also faster TFP growth (TFP growth relationship (5)). This also implies that declining output prices (due to declining input prices) should be associated with faster TFP growth (TFP growth relationship (1)). The relationships between TFP growth and factor shares (TFP growth relationships (2) to (4)) are same as for the previous model.

\section{NEW ZEALAND INDUSTRY TFP GROWTH RELATIONSHIPS}

\subsection{Main estimates}

Given our limited number of observations, the TFP growth relationships were at first estimated for the entire economy (i.e. across all 20 industries). However, the results obtained may be misleading for two reasons. First, the TFP growth relationships may differ across major sub-sectors of the economy, e.g. there might be a closer relationship between factor shares and TFP growth in the manufacturing sector compared to the services sector. Secondly, there are major measurement problems associated with primary and services industries which suggest that poor data quality might greatly affect the estimates. Data for the manufacturing industries are generally of better quality. Unfortunately, we could not determine which reason might be the more important in our case. 
The approach taken, therefore, was to report TFP growth relationship estimates for two data samples, i.e. the entire economy (sample 1) and manufacturing industries only (sample 2), in order to assess whether this produced different results. ${ }^{10}$ In case of differences, estimates for sample 2 are our preferred estimates. However, this may have introduced a bias against exogenous growth theory. Feenstra et al. (1999), for example, have commented that the hypothesis of endogenous growth better fits manufacturing industries. This problem can only be remedied when the quality (and quantity) of NZ data for non-manufacturing industries improves. It might mean, however, that extra care has to be taken when comparing our preferred results to those obtained by studies using aggregate economy-wide data, as is common in time-series based approaches to empirical growth research on the NZ economy (e.g., Oxley et al., 1999).

Table 1 reports the main regression estimates. They have been obtained using a generalised least squares (GLS) estimator for pooled data, which produces Whiteadjusted standard errors and corrects for within cross-section heteroskedasticity. ${ }^{11}$ To test for the impact of possible outliers, dfbeta statistics were calculated. Dropping potential outliers did not change the signs and statistical significance of the point estimates.

\section{[put Table 1 about here]}

\footnotetext{
${ }^{10}$ Engelbrecht and McLellan (2001) also reported estimates for a third data sample, i.e. primary and manufacturing industries. They were very similar to those obtained for the entire economy sample.

${ }^{11}$ We first estimated the TFP growth relationships using OLS. However, the presence of heteroscedasticity resulted in larger standard errors and mostly statistically insignificant point estimates (see Engelbrecht and McLellan, 2001).
} 
A consistent result was obtained for the first TFP growth relationship. Industries with relatively higher TFP growth experienced relative price declines. However, the relative price declines were less than proportional to TFP growth for the whole economy, but more than proportional for manufacturing industries. The numerical value (in absolute terms) of the parameter estimate for sample 2 is larger than that reported by Klenow for US manufacturing industries.

Consistent coefficient estimates in the sense of having the same sign across both data samples were also obtained for TFP growth relationships (2) and (4), and most of relationship (5). There are positive coefficient estimates for LS, and negative coefficients estimates for CS and MS. It seems that industries that displayed high TFP growth were generally less capital- and materials-intensive, and more labour-intensive than other industries. This pattern of results is the opposite of that reported by Klenow (1998). Rapidly declining share-weighted building and construction prices, and rapidly rising share-weighted capital goods prices (and to a lesser extend materials input prices) are associated with high TFP growth (growth relationship (5)). This also contrasts with Klenow, who reports that in the US, fast TFP growth was associated with rapidly declining share-weighted capital and materials prices. ${ }^{12}$

One noticeable exception to the general consistency of estimates for factor shares across our data samples is with respect to NPLS. For sample 1, NPLS is negatively related to

${ }^{12}$ One may speculate that our results reflect the import-dependent nature of the NZ economy, particularly in regard to machinery and equipment, but further exploration of this issue is beyond the scope of this study. 
TFP growth. For sample 2, it is positively related to TFP growth. Klenow found a negative relationship between TFP growth and his human capital proxies.

There is the possibility that NPLS might be a weak proxy for human capital. It is one measure of industry human capital intensity, based on the assumption that nonproduction workers earn a higher wage relative to production workers due to their higher stock of human capital. This assumption does not entirely hold true in the NZ case. While professional, technical, and managerial workers earned a higher wage than did agricultural workers, transport workers, and labourers (i.e. production workers), this was not the case for clerical, sales, and service workers (see Diewert and Lawrence, 1999, p. 244). In addition, while a greater percentage of professional, technical and managerial workers held post-school qualifications ${ }^{13}$ compared to production workers, the opposite was true for clerical, sales, and service workers (Statistics New Zealand, 1997a). This implies that the human capital intensity proxy used in Klenow's (1998) study is an imperfect one in the NZ context. Hence, our results with regard to human capital need to be treated with some caution. Human capital measurement problems were also emphazised by Oxley et al. (1999) in their comparative study of US and NZ economic growth.

\subsection{Sensitivity analysis}

${ }^{13}$ These include skilled vocational qualifications, intermediate and advanced vocational qualifications, bachelor and higher degrees, and post-school qualifications not specified (Statistics New Zealand, 1997a) 
Given the many data problems, it was imperative to conduct further sensitivity analyses of the main results shown in Table 1. In the following, we report estimates obtained using alternative capital stock measures and growth rates of variables that have been calculated over alternative time horizons.

The relationship between TFP growth and industry human capital intensity was explored further by using the high skilled labour share (HSLS) as an alternative measure for the latter. HSLS is defined as the ratio of compensation of professionals, technical workers, and managerial workers to gross output. It is a superior measure of human capital intensity because this group of workers earns higher wages than do other workers, and because they hold a relatively greater percentage of post-school qualifications. Table 2 presents the results from regressing TFP growth on HSLS. While the absolute values of the estimated coefficients vary somewhat from those reported earlier, the coefficients signs are identical to those obtained when regressing NPLS against TFP growth.

\section{[put Table 2 about here]}

So far we used gross capital stock data when calculating TFP. Diewert and Lawrence (1999) argued that their net capital stock series was superior. We therefore also estimated the TFP growth relationships using their net capital stock data. In addition, Statistics New Zealand (1999, Attachment) provides an alternative capital stock series for manufacturing industries at the 2-digit level, which we have also used as part of our sensitivity analysis. The alternative regression estimates are reported in Table 3. Coefficient estimates have the same signs as those reported in Table 1, but estimates are mostly somewhat lower in 
absolute value (those for TFP growth relationship 4, sample 2, are much lower than before). There are also appreciable differences in the explanatory power of the regressions, as indicated by the adjusted $\mathrm{R}^{2}$, but no consistent pattern emerges. For sample 1, the explanatory power increases for four out of five regressions, whereas for sample 2, it only increases for two out of five (and declines for the others).

\section{[put Table 3 about here]}

Finally, the use of alternative time horizons was explored. When the TFP growth relationships were estimated over three year periods, many of the parameter estimates became statistically insignificant. This is not surprising given the sensitivity of short-run growth rates to the business cycle. They are ill suited for investigating the long-run properties of the data. When the TFP growth relationships were estimated over nine year periods, we ran into problems of micronumerosity (too few observations). Thus, the results based on growth rates calculated over six-year time horizons seem the most appropriate for our data set.

\section{COMPARISON OF GROWTH MODEL PREDICTIONS AND NEW ZEALAND ESTIMATES}

We can now compare the predictions for the TFP growth relationships derived from the alternative growth models with our regression estimates. A summary of this comparison is provided in Table 4, and discussed below. 
The exogenous growth model seems consistent with the first TFP growth relationship (this is indicated by a 'Yes' in Table 4). However, the estimates might suggest a higher elasticity of substitution than is implied by the CD production function, resulting in less than proportionate price declines (especially when alternative physical capital stock data are used). The exogenous growth model does not predict that TFP should be negatively related to NPLS (sample 1), MS and CS, nor that it should be positively related to LS, and NPLS (sample 2). These cases are indicated by a 'No' in Table 4.

The general human capital accumulation model does not predict TFP growth relationship (1), i.e. the estimates obtained are inconsistent with it. The model does predict a positive coefficient estimate for labour's share (growth relationship (2)), which holds for both data samples. In order to evaluate the consistency of this model with the remaining TFP growth relationships, it is necessary to consider how labour's share is correlated with the other variables. In both samples, LS is positively correlated with NPLS, i.e. we expect a positive and statistically significant point estimate for TFP growth relationship (3), which is not the case for sample 1, but is the case for sample 2. For both samples labour's share is negatively correlated with capital's and materials' share. Thus the coefficient estimates for growth relationship (4) are consistent with this model. In sample 1, labour's share is basically uncorrelated with share-weighted input price changes, which does not accord with parameter estimates for growth relationship (5). In sample 2, the correlation between LS and CSBC/CSPMTE is negative, which again is not born out by the parameter estimates. This also follows for TFP growth and MSMDEF. 


\section{[put Table 4 about here]}

The model of industry-specific human capital accumulation seems consistent with TFP growth relationship (1) for both samples. The assumption that the covariance between labour intensity and human capital intensity is zero, however, is not fulfilled in our data samples, with LS being positively correlated with NPLS. We therefore add a question mark after the entry in Table 4. The model's prediction that TFP growth and industryspecific human capital (NPLS) are positively related is confirmed for sample 2, but not for sample 1. Because LS is positively correlated with NPLS, we expect the same sign for both coefficient estimates. This is only the case for sample 2. Because NPLS is negatively correlated with material's share and capital's share, negative coefficient estimates were expected on CS and MS (TFP growth relationship (4)) for sample 2 (and positive coefficients for sample 1). A similar story to that for the previous model applies to growth relationship (5).

Turning to the general idea accumulation model, it can be seen that the expectation for TFP growth relationship (1) is confirmed qualitatively for both data samples, i.e. the parameter estimates have the expected sign. However, in most cases, the expectation is not confirmed quantitatively (coefficient estimate greater than one in absolute terms). We

therefore add a question mark after the entry in Table 4. The expectation that the coefficient estimates for LS are negative, and those for CS and MS positive and statistically significant, is not born out in the NZ case. According to this model, NPLS 
should be negatively related to TFP growth. This is the case for sample 1, but not sample 2. The model cannot explain TFP growth relationship (5).

Finally, the industry-specific idea accumulation model differs from the general idea accumulation model in that it is expected that faster TFP growth is associated with declining capital and materials deflators. This potentially affects our expectation for TFP growth relationship (5). The expectation for growth relationship (5) is not confirmed, however. Growth relationship (1) is again confirmed and growth relationships (2-4) are not confirmed, with the exception of growth relationship (3) for sample 1.

\section{CONCLUDING REMARKS}

Our results summarised in Table 4 indicate that none of the growth models seem to be able to explain all of the TFP growth relationships estimated from the NZ data. Taken at face value, however, the rival human capital models, especially the industry-specific human capital model, come the closest for our preferred sample 2.

On the one hand, these results might seem surprising. Skill levels in NZ are not high by OECD standards, although they have been increasing over time (Galt, 2000). Also, one could argue that NZ's TFP growth ought to benefit a lot from knowledge spillovers embodied in capital and intermediate goods imports. The fact that idea accumulation models seem to perform worse than rival human capital models might be an indication that NZ has been weak in absorbing international $R \& D$ spillovers. This would indicate 
the need for NZ-specific research that more directly focuses on international (and national) knowledge spillovers. ${ }^{14}$

On the other hand, others who have researched NZ's economic growth have pointed out its idiosyncratic character over long periods of time, with the country emerging as an oddity, outside any natural grouping of economies (Greasley and Oxley, 2000). In short, NZ's growth experience might not conform to any of the major growth models currently in vogue.

Overshadowing these speculations are the many data problems in the NZ case, which imply that our findings have to be treated with due caution. They do not easily lend themselves to policy advice, except perhaps to the mostly uncontroversial and widely accepted advice that the human capital stock of NZ's workforce should be upgraded, including the upgrading of industry-specific human capital stocks through immigration. This, however, is only supported for our preferred data sample, i.e. the manufacturing sector.

With regard to the second major aim of this paper, it should be noted that our findings contrast sharply with those of Klenow (1998). He finds that the 'ideas' class of endogenous growth models seems the most appropriate for US manufacturing industries, with the industry-specific idea accumulation model being able to explain all TFP growth

\footnotetext{
${ }^{14}$ One of the authors (Engelbrecht, 1997) has provided some evidence that foreign R\&D spillovers have had a negative impact on NZ's TFP growth over the period 1971-1990. This may have been due to a relatively small domestic R\&D capital stock, resulting in a low capacity to absorb foreign R\&D. This is further supported by NZ's relatively weak National Innovation System (Engelbrecht and Darroch, 1999).
} 
relationships. Our estimates seem to confirm Klenow's (ibid., p. 21) hunch that his findings "might be peculiar to US manufacturing industries. They may not extend to nonmanufacturing industries or to other countries”. More empirical studies are needed to establish how well the different endogenous growth models capture the experiences of different economies.

Last but not least, Klenow also noted that rival human capital accumulation models and idea accumulation models are not mutually exclusive, and that both surely contribute to growth. In fact, a hybrid model of idea and human capital accumulation would show up in the empirics as a rival human capital model, and yet would basically have idea model policy prescriptions (ibid., p. 5). Given this fact, one might regard Klenow's strong findings in favour of idea accumulation models as surprising, not our findings in favour of rival human capital models. There is a need for further research that develops sharper empirical tests capable of distinguishing between the applicability of the different growth models. 


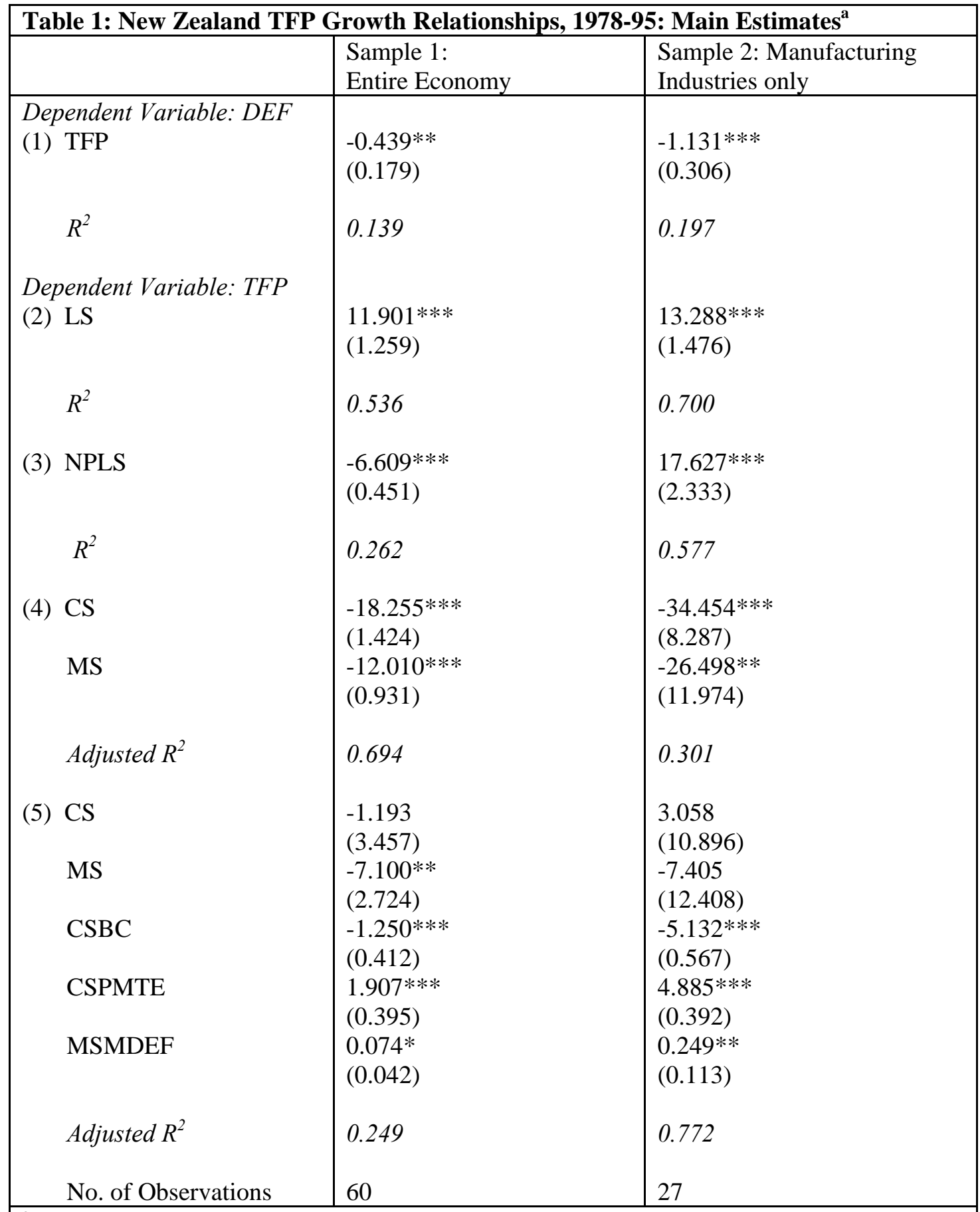

\footnotetext{
${ }^{\mathrm{a}}$ The regressions have been estimates using a generalized least squares estimator. Whiteadjusted standard errors are in parentheses. Each observation is a six-year average. Three stars $(* * *)$ indicate that the coefficient is significantly different from zero at the $1 \%$ level, two stars $(* *)$ indicate that it is significant at the $5 \%$ level, and one star $(*)$ indicates that it is significant at the $10 \%$ level.
} 
Table 2: TFP Growth and High Skilled Labour Share ${ }^{\mathrm{a}}$

\begin{tabular}{|c|c|c|}
\hline $\begin{array}{l}\text { Dependent Variable: } \\
\text { TFP }\end{array}$ & $\begin{array}{l}\text { Sample 1: } \\
\text { Entire Economy }\end{array}$ & $\begin{array}{l}\text { Sample 2: } \\
\text { Manufacturing } \\
\text { Industries only }\end{array}$ \\
\hline HSLS & $\begin{array}{l}-9.810 * * * \\
(1.616)\end{array}$ & $\begin{array}{l}14.437 * * * \\
(3.047)\end{array}$ \\
\hline$R^{2}$ & 0.318 & 0.513 \\
\hline No. of observations & 60 & 27 \\
\hline \multicolumn{3}{|c|}{$\begin{array}{l}\text { a The regressions have been estimates using a generalized least squares estimator. } \\
\text { White-adjusted standard errors are in parentheses. Each observation is a six-year } \\
\text { average. Three stars }\left({ }^{* *}\right) \text { indicate that the coefficient is significantly different } \\
\text { from zero at the } 1 \% \text { significance level. }\end{array}$} \\
\hline
\end{tabular}




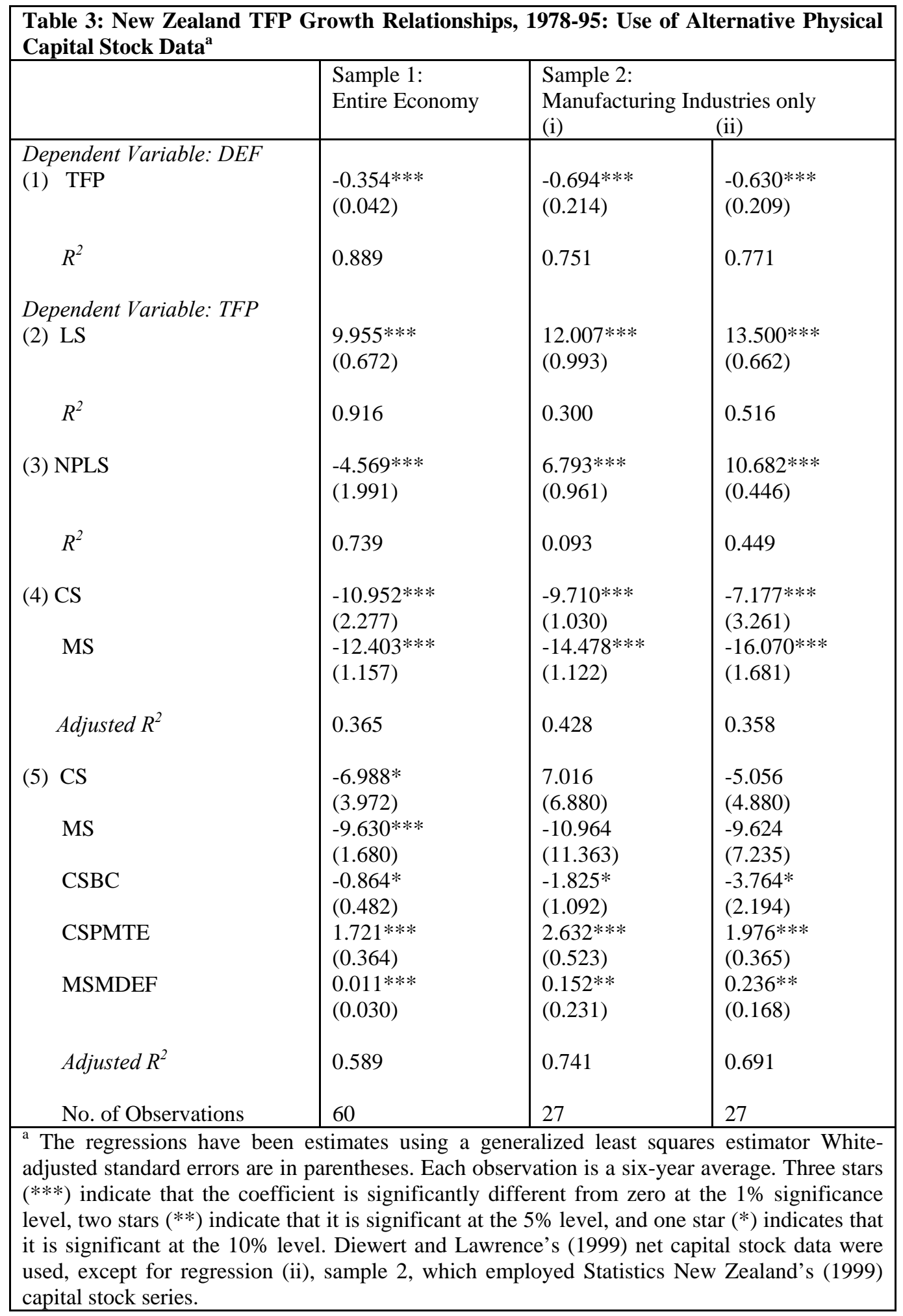


Table 4: Summary of Results: Model Predictions Versus Empirics of TFP Growth Relationships

\begin{tabular}{|l|l|l|l|l|l|}
\hline \multirow{2}{*}{} & \multicolumn{5}{|l|}{ Growth Models } \\
\cline { 2 - 6 } & Exogenous & $\begin{array}{l}\text { General } \\
\text { Human } \\
\text { Capital }\end{array}$ & $\begin{array}{l}\text { Specific Human } \\
\text { Capital }\end{array}$ & $\begin{array}{l}\text { General Idea } \\
\text { Accumul. }\end{array}$ & $\begin{array}{l}\text { Specific Idea } \\
\text { Accumulation }\end{array}$ \\
\hline $\begin{array}{l}\text { TFP } \\
\text { Growth } \\
\text { Relations.: }\end{array}$ & $\begin{array}{l}\text { Samples } \\
1 \quad\end{array}$ & $\begin{array}{l}\text { Samples } \\
1 \quad\end{array}$ & $\begin{array}{l}\text { Samples } \\
12\end{array}$ & $\begin{array}{l}\text { Samples } \\
12\end{array}$ & $\begin{array}{l}\text { Samples } \\
2\end{array}$ \\
\hline$(1)$ & Yes, Yes & No, No & Yes?, Yes? & Yes?, Yes? & Yes, Yes \\
\hline$(2)$ & No, No & Yes, Yes & No, Yes & No, No & No, No \\
\hline$(3)$ & No, No & No, Yes & No, Yes & Yes, No & Yes, No \\
\hline$(4)$ & No, No & Yes, Yes & No, Yes & No, No & No, No \\
\hline$(5)$ & No, No & No, No & No, No & No, No & No, No \\
\hline
\end{tabular}

Note: 'Yes' ('No') indicates that the growth model can (cannot) explain the TFP growth relationship estimates. A '?' indicates that one of the model assumptions or quantitative expectation is contradicted by our data/estimates. 


\section{APPENDIX A - SECTOR CLASSIFICATION}

The ONZPRDB contains data on the following industries that comprise the market sector of the NZ economy (Diewert and Lawrence, 1999, Table 4.1, p. 37):

1. Agriculture

2. Fishing and Hunting

3. Forestry and Logging

4. Mining and Quarrying

5. Food and Tobacco

6. Wood and Wood Products

7. Pulp and Paper Products, Printing, and Publishing

8. Basic Metal Products

9. Textiles, Clothing, and Footwear

10. Petroleum, Chemical, Plastics, and Rubber Products

11. Non Metallic Mineral Products

12. Machinery and Equipment

13. Other Manufacturing

14. Electricity, Gas, and Water

15. Construction

16. Trade, Restaurants, and Hotels

17. Transport and Storage

18. Communications

19. Finance, Insurance, Real Estate, and Business Services 
20. Community, Social, and Personal Services

Industries 1-4 constitute the primary sector and industries 5-13 constitute the manufacturing sector. Industries 14 and 15 are often classified as support industries and added to the manufacturing sector to make up the secondary sector. Industries 16-20 constitute the services (tertiary) sector.

\section{APPENDIX B - DATA DESCRIPTION AND SOURCES}

\section{Gross Output and Value Added}

Data on real and nominal gross output for the twenty industries was drawn from the Annual Production Accounts of the ONZPRDB. Real Production GDP by industry (\$1992 million) was obtained from the ONZPRDB (Diewert and Lawrence, 1999, Table C1, pp. 291-292). Likewise, information on Nominal Production GDP was taken from the ONZPRDB (ibid., Table C2, pp. 293-294). The output price deflator series was calculated by dividing nominal observations by real observations.

\section{Labour Input}

The labour input used in this paper is an 'hours worked' labour series, taken from the ONZPRDB (ibid., Table C5, pp. 297-298). This series was formed using three data sources: the Household Labour Force Survey (HLFS), the Quarterly Employment Survey (QES), and the Economic Survey of Manufacturing (ESM). Chapple and Keegan (1998, 
p. 21) advise that this labour series should be used with "extreme caution," given different sources across industry and through time. They note that the manufacturing sector has the most reliable 'hours worked' series, Agriculture and Fishing the least reliable. The remaining industries lie somewhere in between.

\section{(Physical) Capital Stock Input}

The real gross and net capital stock series (\$1992 million) were drawn from the ONZPDB (Diewert and Lawrence, 1999, Tables C12-C15, pp. 312-319). The procedure used for calculating real gross and net capital stocks is outlined in Diewert and Lawrence (1999, Appendix D, pp. 332-339). Capital deflators were taken from the ONZPRDB (Chapple, 1999). An alternative capital stock series (Statistics New Zealand, 1999, Attachment) was also employed as part of the sensitivity analysis.

\section{Materials Input}

The materials input was calculated by finding the difference between nominal gross output and nominal value added. This corresponds to nominal intermediate consumption in the Annual Production Accounts. Real materials input was found by deflating nominal materials input by the input deflator from the ONZPRDB.

\section{Factor Shares}

Factor shares were calculated using data from the Annual Production Accounts (Chapple, 1999) and census data (Statistics New Zealand, 1977, 1987, and 1997b). Labour's share 
was calculated by dividing compensation of employees by nominal gross output ${ }^{15}$; capital's share by dividing operating surplus by nominal gross output; and materials share as a residual, by subtracting labour's and capital's share from one. Nonproduction labour's share was calculated in the following way. First, the number of nonproduction workers (professionals, technical, managerial, clerical, service, and sales workers) for each industry was obtained. Then the corresponding average estimated ordinary-time earnings for nonproduction workers were multiplied by the number of nonproduction workers. This figure was then divided by the corresponding average nominal gross output figure. High-skilled labour's share was found in a similar manner.

${ }^{15}$ This is likely to have understated labour's share (particularly in sectors such as Agriculture and Fishing), because compensation of employees excludes payments made to self-employed persons. 


\section{References}

Aghion, P. and P. Howitt (1998). Endogenous Growth Theory. MIT Press, Cambridge, Mass.

Basu, S. and J. Fernald (1995). Are Apparent Productive Spillovers a Figment of Specification Error? Journal of Monetary Economics, 36, pp. 165-188.

Basu, S. and J. Fernald (1997). Returns to Scale in U.S. Production: Estimates and Implications. Journal of Political Economy, 105, pp. 249-283.

Bernanke, B. and R. Gürkaynak (2001). Is Growth Exogenous? Taking Mankiw, Romer, and Weil Seriously. NBER Working Paper No. 8365.

Bruno, M. (1984). Raw Materials, Profits, and the Productivity Slowdown. The Quarterly Journal of Economics, 99, pp. 1-29.

Campbell, C. (1984). Explaining Efficiency-Growth in New Zealand Manufacturing Industries. Research Project on Economic Planning 77, Victoria University of Wellington.

Chapple, S. (1999). Personal communication.

Chapple, S. and A. Keegan (1998). Documentation of the Database Compiled to be used in New Zealand Productivity Research. Reserve Bank of New Zealand, Wellington.

Dalziel, P. and R. Lattimore (1999). The New Zealand Macroeconomy: A Briefing on the Reforms, $3^{\text {rd }}$ Edition. Oxford University Press, Auckland.

Diewert, W.E. and D. A. Lawrence (1999). Measuring New Zealand's Productivity, Treasury Working Paper 99/5, Wellington: New Zealand Treasury. http://www.treasury.govt.nz/workingpapers/1999/99-5.asp

Durlauf, S. and D. Quah (1999). The New Empirics of Economic Growth. In Taylor, J. and M. Woodford (eds.), Handbook of Macroeconomics, Volume 1A. Elsevier Science B.V., Amsterdam.

Engelbrecht, H.-J. (1997). International R\&D Spillovers Amongst OECD Economies. Applied Economics Letters, 4, pp. 315-319.

Engelbrecht, H.-J. and J. Darroch (1999). A Comparative Macro-level Assessment of New Zealand’s ‘National Innovation System’. Prometheus, 17, pp. 283-298. 
Engelbrecht, H.-J. and N. McLellan (2001). Economic Growth Revisited: Identifying a Class of Growth Models for the New Zealand Economy. Discussion Paper No. 01.10, Department of Applied and International Economics, Massey University, New Zealand. http://econ.massey.ac.nz/Publications/discuss/dp01-10.pdf

Evans, L., Grimes, A., Wilkinson, B. and D. Teece (1996). Economic Reform in New Zealand 1984-95: The Pursuit of Efficiency. Journal of Economic Literature, 34, pp. 1856-1902.

Feenstra, R., Madani, D., Yang, T.-H. and C.-Y. Liang (1999). Testing Endogenous Growth in South Korea and Taiwan. Journal of Development Economics, 60, pp. 317-341.

Funke, M. and H. Strulik (2000). On Endogenous Growth with Physical Capital, Human Capital and Product Variety. European Economic Review, 44, pp. 491-515.

Galt, D. (2000). New Zealand's Economic Growth. Treasury Working Paper 00/09, New Zealand Treasury, Wellington. http://www.treasury.govt.nz/workingpapers/2000/00-9.asp

Greasley, D. and L. Oxley (2000). Outside the Club: New Zealand's Economic Growth, 1870-1993. International Review of Applied Economics, 14, pp. 173-192.

Jones, C.I. (1995a). Time Series Tests of Endogenous Growth Models. The Quarterly Journal of Economics, 110, pp. 495-525.

Jones, C.I. (1995b). R\&D-Based Models of Economic Growth. Journal of Political Economy, 103, pp. 757-784.

Klenow, P.J. (1998). Ideas Versus Rival Human Capital: Industry Evidence on Growth Models. Journal of Monetary Economics, 42, pp. 3-23.

Klenow, P.J. and A. Rodriguez-Clare (1997). Economic Growth: A Review Essay. Journal of Monetary Economics, 40, pp. 597-617.

Kocherlakota, N. R. and K.-M. Yi (1996). A Simple Time Series Test of Endogenous vs. Exogenous Growth Models: An Application to the United States. Review of Economics and Statistics, 78, pp. 126-134.

Kocherlakota, N. R. and K.-M. Yi (1997). Is There Endogenous Long-Run Growth? Evidence from the United States and the United Kingdom. Journal of Money, Credit, and Banking, 29, pp. 235-262.

Oxley, L., Zhu, S. and D. Greasley (1999). Endogenous versus Exogenous Growth: USA and New Zealand Compared. Singapore Economic Review, 44, pp. 26-56. 
Rebelo, S. (1991). Long-run Policy Analysis and Long-run Growth. Journal of Political Economy, 99, pp. 500-521.

Romer, P.M. (1990). Endogenous Technical Change. Journal of Political Economy, 98(5), Part 2, pp. S71-S102.

Silverstone, B., Bollard, A. and R. Lattimore (eds.)(1996). A Study of Economic Reform: The Case of New Zealand. Elsevier Science B.V., Amsterdam.

Statistics New Zealand (1977). 1976 Census of Population and Dwellings. Wellington.

Statistics New Zealand (1987) 1986 New Zealand Census of Population and Dwelling, Series C, Report 4. Wellington.

Statistics New Zealand (1997a). 1996 Census Education.Wellington.

Statistics New Zealand (1997b). 1996 Census Employment and Unemployment. Wellington.

Statistics New Zealand (1999). Official Capital Stock Estimates.Wellington.

Temple, J. (1999). The New Growth Evidence. Journal of Economic Literature, 37, pp. 112-156. 